\title{
Apologia de um louco
}

\section{Apology of a Madman}

Autor: Piotr Iákovlevitch Tchaadáiev

Tradutor: Théo Amon

Edição: RUS Vol. 11. N 16

Data: Junho 2020

https://doi.org/10.11606/issn.2317-4765.rus.2020.169929 


\section{Apologia de um louco ${ }^{1}$}

Piotr lákovlevitch Tchaadáiev Théo Amon*

\section{Introdução}

* Doutorando do Programa de Pós-Graduação em Letras da Universidade Federal do Rio Grande do Sul. Mestre em Letras - Estudos de Literatura (2019), pela Universidade Federal do Rio Grande do Sul - UFRGS. Tradutor independente de inglês, alemão, francês e espanhol. Coordenação de Aperfeiçoamento de Pessoal de Nível Superior (CAPES); https://orcid.org/0000-0002-03483234; theoamon@gmail.com
O texto a seguir trata-se de uma tradução integral de Apologie d'un fou (1836/7), que Piotr Tchaadaiév (1794-1856) redigiu após ter sido declarado oficialmente insano como represália à sua Primeira carta filosófica (1829). Nesta, de inspiração idealista e foco religioso, o autor defende a ideia de que a Rússia não tinha ainda uma história civilizacional própria, vivendo de importações precárias que não decorriam de um progresso moral e intelectual orgânico. Em tom fatalista, Tchaadaiév constatava que, prensada entre Europa e Ásia, a Rússia nada aprendera com o tempo. Ela seria uma nulidade cultural, retrógrada, em trágica solidão histórica. Sem um passado integrado à cristandade católica e ao desenvolvimento filosófico-político da Europa, a Rússia ainda estava de fora da cultura

1 Fonte: Euvres choisies de Pierre Tchadaief, publiées pour la première fois par le P. Gagarin de la compagnie de Jésus, Paris-Leipzig, Librairie A. Franck, 1862. Transcrição digital disponibilizada online pela Bibliothèque russe et slave em 25 de abril 2019 (https://bibliotheque-russe-et-slave.com/Livres/Tchaadaiev___Apologie_d_un_fou.pdf). 
moderna do Ocidente. Inicialmente um manuscrito (em francês) com bastante circulação, esse texto acabou sendo publicado (1836), em tradução russa, no periódico $O$ telescópio. $O$ escândalo foi tamanho que a revista foi extinta, o editor, exilado, e o censor responsável, destituído. Tchaadaiév foi detido como louco, proibido de publicar, e por um mês foi obrigado a receber periodicamente a visita de um policial e um alienista para atestar que continuava insano e deveria seguir em prisão domiciliar. A Apologia de um louco, escrita também em francês, aparentemente se tornaria um pequeno tratado de filosofia da história aplicada ao caso russo, no qual o autor retificaria posições extremas da Carta filosófica, mas também defenderia o fundamento do seu raciocínio e o desenvolveria em novas direções. Porém, a obra não evoluiu além do fragmento que aqui traduzimos, publicado postumamente em 1862. É um dos documentos fundamentais da futura polêmica entre eslavistas e ocidentalistas, que alternadamente reclamariam para si o impulso dado por Tchaadaiév.

"Oh, meus irmãos! Eu disse A mais amarga verdade, mas sem amargor."

Coleridge

A caridade, diz São Paulo, tudo desculpa, tudo crê, tudo suporta: assim, desculpemos, creiamos, suportemos tudo, sejamos caridosos. Mas, primeiro, a catástrofe que acaba de mutilar a nossa existência intelectual de maneira tão estranha, jogando ao vento o labor de toda uma vida, no fundo nada mais é que o resultado do grito sinistro lançado por uma certa extensão da sociedade quando da aparição do nosso artigo, essa página pungente, se preferirdes, mas que certamente merecia qualquer outra coisa que não os clamores com que foi saudada. 
O governo, no fim das contas, fez apenas o seu dever; pode-se mesmo dizer que os rigores exercidos contra nós neste momento nada têm de exorbitante, pois é certo que estão longe de ter superado o que um numeroso público esperava. $\mathrm{O}$ que quereis que faça um governo bem-intencionado além de se conformar ao que ele acreditar ser, em boa-fé, a expectativa séria do país? Quanto aos clamores públicos, são algo bem diverso. Há diversas maneiras de amar a sua pátria: o samoiedo, por exemplo, que ama as neves natais que o deixaram míope, a tenda enfumaçada onde ele passa enrodilhado a metade dos seus dias, a gordura rançosa das suas renas que 0 cerca de uma atmosfera nauseabunda, certamente não ama $o$ seu país do mesmo modo que o cidadão inglês, orgulhoso das instituições e da alta civilização da sua ilha gloriosa; e sem dúvida seria vexatório para nós se ainda prezássemos à moda dos samoiedos os lugares que nos viram nascer. $\mathrm{O}$ amor à pátria é uma coisa belíssima, mas existe coisa melhor: o amor à verdade. $\mathrm{O}$ amor à pátria faz os heróis; $\mathrm{o}$ amor à verdade, os sábios, os benfeitores da humanidade. É o amor à pátria que divide os povos, que nutre os ódios nacionais, que às vezes cobre a terra de luto; é o amor à verdade que propaga as luzes, que cria as alegrias do espírito, que aproxima os homens da Divindade. Não é pelo caminho da pátria, mas pelo caminho da verdade que se sobe ao céu. É verdade que nós, russos, sempre nos preocupamos mediocremente com o que é verdadeiro ou falso. Portanto, não se deve guardar nenhuma mágoa do país se ele é vivamente abalado por uma apóstrofe, das menos virulentas, dirigida às suas debilidades. Eu tampouco guardo rancor, garanto-vos, do caro público que por tanto tempo vestiu peles de cordeiro comigo; é com sangue frio, sem qualquer irritação, que tento fazer o balanço da minha estranha situação. Não é necessário, pergunto-vos, que eu busque descobrir, se puder, em que pé está junto aos seus semelhantes, junto aos seus concidadãos, junto ao seu Deus, o homem condenado à demência por uma sentença da justiça suprema do país?

Eu nunca disputei as ovações populares, nem procurei os favores da multidão; sempre pensei que o gênero humano só devia caminhar seguindo seus chefes naturais, os ungidos pelo 
Senhor; que ele só saberia avançar nos caminhos do seu verdadeiro progresso guiado pelos que, de uma maneira ou outra, receberam diretamente do céu a missão e o poder de conduzi-lo; que a razão geral não era a razão absoluta, como acreditava um grande escritor do nosso tempo; que os instintos das maiorias eram infinitamente mais apaixonados, estreitos e egoístas que os do homem isolado; que aquilo que se chama de bom senso do povo não era nem de perto o bom senso; que a verdade não emanava da turba; que ela não poderia ser representada por um número; enfim, que a inteligência humana nunca se manifesta em toda a sua potência, em todo o seu esplendor, senão no espírito solitário, centro e sol da sua esfera. Como então aconteceu que eu, um belo dia, me tenha encontrado face a um público em cólera, um público cujo sufrágio eu jamais ambicionara, cujos afagos jamais me alegraram, cujas troças jamais me atingiram? Como aconteceu que uma ideia que não era dirigida ao meu século, que, sem querer mexer com os homens do nosso tempo, eu legara do mais profundo das minhas convicções às gerações por vir, às gerações mais bem informadas, e com esse caráter de publicidade íntima que ela já adquirira muito tempo antes, como aconteceu que essa ideia tenha rompido seus entraves, escapado da sua clausura, precipitado-se para a rua, investindo no meio da multidão estupefata? É isso o que eu não saberia dizer. Porém, eis o que eu posso afirmar com perfeita segurança.

Faz trezentos anos que a Rússia aspira a se confundir com o ocidente da Europa, extraindo de lá todas as suas ideias mais sérias, todos os seus ensinamentos mais fecundos, todas as suas alegrias mais vivas. Há mais de um século para cá, ela faz mais que isso. O maior dos nossos reis, aquele que, diz-se, iniciou uma nova era para nós, a quem, diz-se, devemos a nossa grandeza, nossa glória e todos os bens que possuímos hoje, abjurou (isso faz cento e cinquenta anos) da velha Rússia na frente do mundo inteiro. Com seu sopro poderoso, ele varreu todas as nossas instituições; cavou um abismo entre o nosso passado e o nosso presente, jogando nele todas as nossas tradições confundidas. Foi ele mesmo aos países do Ocidente para se apequenar, voltando maior para nós; prosternou-se 
diante do Ocidente, reerguendo-se nosso mestre e legislador. Introduziu no nosso idioma os idiomas do Ocidente; sua nova capital, chamou-a com um nome do Ocidente; seu título hereditário, rejeitou-o e tomou um título do Ocidente; por fim, quase renunciou ao seu próprio nome, e mais de uma vez assinou seus decretos soberanos com um nome do Ocidente. Desde essa época, com os olhares constantemente voltados aos países do Ocidente, nada mais fizemos, por assim dizer, que aspirar as emanações que nos chegavam de lá e delas nos alimentar. Nossos príncipes, cumpre dizer, que quase sempre nos levaram pela mão, que quase sempre rebocaram o país, sem que este respondesse por nada, eles mesmos nos impuseram os costumes, a linguagem, a indumentária do Ocidente. Nós aprendemos a soletrar os nomes das coisas com os livros do Ocidente. Nossa própria história foi um dos países do Ocidente que nos ensinou; nós traduzimos a literatura inteira do Ocidente, decoramo-la, apropriamo-nos dos seus farrapos; e, finalmente, ficamos contentes em nos parecermos com o Ocidente, e exultantes quando ele houve por bem nos contar entre os seus.

Foi bela, convenhamos, essa criação de Pedro, o Grande, essa ideia poderosa que se apoderou de nós e nos lançou no caminho que percorreríamos com tanto brilho; foi profunda essa palavra que nos disse: "Vede aquela civilização, fruto de tantos trabalhos, essas ciências, essas artes que custaram tantos suores a tantas gerações! Tudo isso é vosso contanto que vos despojeis das vossas superstições, repudieis vossos preconceitos, não sejais zelosos do vosso passado bárbaro, não vos jacteis dos vossos séculos de ignorância, não tenhais outra ambição que vos apropriardes das obras de todos os povos, das riquezas adquiridas pelo espírito humano em todas as latitudes do globo". E não era apenas pela sua nação que o grande homem trabalhava. Esses homens da Providência são sempre enviados para a humanidade inteira. Inicialmente, um povo os reclama, depois eles se absorvem no gênero humano, como esses grandes rios que começam fertilizando vastas regiões para depois confiar o tributo das suas águas ao Oceano. O espetáculo que se ofereceu ao universo quando, deixando 
a majestade real e seu país, ele foi se esconder nas últimas fileiras dos povos civilizados, o que foi isso senão um novo esforço do gênio humano, de sair do recinto estreito da pátria para se instalar na grande esfera da humanidade? Essa foi a lição que nos cabia acolher: com efeito, aproveitamo-la, e até o dia de hoje vimos caminhando na via que o grande imperador nos traçou. Nosso imenso desenvolvimento é apenas o cumprimento desse soberbo programa. Nenhum outro povo foi menos enfatuado de si mesmo que o povo russo tal como Pedro, o Grande, o moldou, e nenhum outro povo obteve sucessos mais gloriosos na trilha do progresso. A alta inteligência desse homem extraordinário intuía perfeitamente qual deveria ser o nosso ponto de partida no caminho da civilização e do movimento intelectual do mundo. Ele viu que, como o dado histórico nos faltava praticamente por completo, não conseguiríamos assentar o nosso futuro sobre essa base impotente; entendeu muito bem que, situados em frente à velha civilização da Europa, última expressão de todas as civilizações anteriores, nada tínhamos que nos enfurnar na nossa história, arrastar-nos, como os povos do Ocidente, através do caos dos preconceitos nacionais, nas sendas estreitas das ideias locais, nos carris enferrujados da tradição vernacular; que precisávamos empolgar, com um elã espontâneo das nossas forças internas, com um esforço enérgico da consciência nacional, os destinos que nos estavam reservados. Assim, ele nos livrou de todos esses antecedentes que atulham as sociedades históricas e entravam sua marcha; abriu a nossa inteligência a todas as grandes e belas ideias que existem entre os homens; entregou-nos o Ocidente inteiro, tal como os séculos o haviam feito, e deu-nos como história toda a sua história, como futuro todo o seu futuro.

Credes que, se houvesse encontrado no meio da sua nação uma história rica e fecunda, tradições vivas, instituições profundamente arraigadas, ele não teria hesitado em lançá-la num novo molde? Credes que, na presença de uma nacionalidade fortemente desenhada, fortemente pronunciada, seu instinto de espírito fundador não o teria levado, pelo contrário, a requisitar dessa própria nacionalidade os instrumentos 
necessários para a regeneração do seu país? E o país, por sua vez, teria suportado nesse caso que lhe arrancassem o seu passado, que praticamente lhe impusessem o da Europa? Mas não foi o que aconteceu. Pedro, o Grande, encontrou em casa apenas papel em branco, e com sua forte mão traçou estas palavras, Europa e Ocidente: daí em diante, fomos Europa e Ocidente. Não nos enganemos: quaisquer que tenham sido o gênio desse homem e a enorme energia da sua vontade, sua obra só era possível no seio de uma nação cujos antecedentes não lhe ordenavam imperiosamente a marcha que ela tinha de seguir, cujas tradições não tinham o poder de lhe criar um futuro, cujas lembranças podiam ser impunemente apagadas por um legislador audacioso. Se fomos tão dóceis à voz do príncipe que nos convidava a uma vida nova, é porque aparentemente não tínhamos nada na nossa existência anterior que pudesse legitimar a resistência. $O$ traço mais profundo da nossa fisionomia histórica é a ausência de espontaneidade no nosso desenvolvimento social. Olhai bem e vereis que todo fato importante da nossa história é um fato imposto; cada ideia nova, quase sempre uma ideia importada. Mas não há nada nesse ponto de vista que deva escandalizar o sentimento nacional; se ele é verdadeiro, é mister aceitá-lo, e isso é tudo. Assim como há grandes personagens históricos, há grandes nações que não se poderia explicar pelas leis normais da nossa razão, mas que a lógica suprema da Providência decreta em seu mistério; é a nossa situação; mas, uma vez mais, a honra nacional nada tem que ver com tudo isso. A história de um povo não é apenas uma sequência de fatos que se sucedem - é também uma série de ideias que se encadeiam. É preciso que o fato se traduza em uma ideia; é preciso que um pensamento, um princípio, circule através dos acontecimentos e tenda a se realizar. Assim o fato não se perde, ele sulca as inteligências, fica gravado nos corações, e nenhuma força no mundo pode expulsá-lo deles. Essa história, não é o historiador que a faz - é a força das coisas. Um dia, vem o historiador, encontra-a pronta e a conta; mas vindo ele ou não, nem por isso ela deixa de existir, e cada membro da família histórica, por mais obscuro que seja, por mais ínfimo que seja, carrega-a no fundo do 
seu ser. Essa é precisamente a história que nós não temos. É preciso aprender a viver sem ela, e não apedrejar os que foram os primeiros a se aperceber disso.

Os nossos eslavônicos fanáticos podem muito bem, em suas diversas escavações, exumar de tempos em tempo objetos de curiosidade para os nossos museus e bibliotecas; porém, creio ser lícito duvidar que eles algum dia logrem tirar do nosso solo histórico algo que preencha o vazio das nossas almas, algo que condense a vagueza dos nossos espíritos. Vede a Europa da Idade Média: nenhum evento que não seja, em algum modo, de uma necessidade absoluta, que não tenha deixado traços profundos no coração da humanidade. E por que isso? É que lá, atrás de cada evento encontra-se uma ideia; a história da Idade Média é a história do pensamento dos tempos modernos, buscando encarnar-se na arte, na ciência, na vida do homem, na sociedade. Da mesma forma, quantos sulcos essa história cavou nas inteligências, como ela lavrou o terreno no qual se agita o espírito do homem! Estou ciente de que nem todas as histórias têm a marcha rigorosa, a marcha lógica dessa época prodigiosa, no seio da qual elaborou-se a sociedade cristã sob o império de um princípio supremo; mas não é menos verdade que é esse o verdadeiro caráter do desenvolvimento histórico, seja de um povo, seja de uma família de povos, e que as nações desprovidas de um passado assim constituído devem se resignar a procurar alhures (e não na sua história ou memória) os elementos do seu progresso ulterior. A vida dos povos se comporta mais ou menos como a dos indivíduos. Todos os homens viveram, mas só o homem de gênio ou o homem situado em certas condições peculiares tem uma verdadeira história. Se um povo, por exemplo, por um concurso de circunstâncias que ele não criou, pelo efeito de uma posição geográfica que ele não escolheu, espalhar-se sobre um território de imensa extensão sem ter a consciência do que está fazendo, e acabar sendo um povo poderoso, isso será certamente um fenômeno surpreendente, e pode-se admirá-lo quanto quiser; mas o que quereis que a história diga dele? No fundo, nada mais é que um fato puramente material, um fato, por assim dizer, geográfico, de enormes proporções, sem dúvida, mas nada além disso. A 
história o coletará, o registrará nos seus fastos, depois se fechará sobre ele e tudo estará dito. A verdadeira história desse povo só começará no dia em que ele agarrar a ideia que lhe foi confiada, que ele é chamado a realizar, e quando se puser a persegui-la com esse instinto perseverante, embora oculto, que conduz os povos aos seus destinos. É esse o momento que eu evoco em prol do meu país, com todas as forças do meu coração; é essa a tarefa que eu gostaria de ver-vos empreender, vós, meus caros amigos e concidadãos, que viveis em um século altamente instruído e que acabais de me mostrar tão bem como estais vivamente inflamados do santo amor pela pátria.

O mundo foi sempre, em todas as épocas, dividido em duas partes, Oriente e Ocidente. Essa não é somente uma divisão geográfica: é também uma ordem de coisas resultante da própria natureza do ser inteligente, são dois princípios que respondem às duas forças dinâmicas da natureza, duas ideias que cingem toda a economia do gênero humano. Foi concentrando-se, recolhendo-se, fechando-se sobre si mesmo que o espírito humano se construiu em Oriente; foi estendendo-se para fora, irradiando-se em todos os sentidos, lutando contra todos os obstáculos, que ele se desenvolveu em Ocidente. A sociedade se constituiu naturalmente sobre esses dados primitivos. No Oriente, o pensamento retirado em si mesmo, refugiado no repouso, escondido no deserto, deixou o poder social como mestre de todos os bens da terra; no Ocidente, a ideia que se projeta em toda parte, que abraça todas as necessidades do homem, que aspira a todas as venturas, fundou o poder sobre o princípio do direito; entretanto, tanto numa quanto na outra dessas esferas, a vida foi forte e fecunda; tanto numa quanto na outra, as altas inspirações, os pensamentos profundos, as criações sublimes não faltaram à inteligência humana. O Oriente veio primeiro e derramou na terra ondas de luz vindas do seio da sua meditação solitária; depois veio o Ocidente, que, com sua imensa atividade, sua palavra viva, sua análise todo-poderosa, tomou conta dos trabalhos, terminou o que o Oriente começara e, por fim, envolveu-o em seu vasto amplexo. Porém, no Oriente, as inteligências dóceis, ajoelhadas perante a autoridade do tempo, esgotaram-se no exercí- 
cio da sua submissão absoluta a um princípio venerado e, um dia, adormeceram aprisionadas em sua síntese imóvel, sem imaginar os destinos novos que se preparavam para elas; ao passo que, no Ocidente, elas caminhavam orgulhosas e livres, inclinando-se apenas perante a autoridade da razão e do Céu, detendo-se apenas perante o desconhecido, e com os olhos sempre fixados no futuro sem limites. E elas seguem caminhando, vós o sabeis, e sabeis também que, a partir de Pedro, o Grande, nós acreditávamos caminhar com elas. Mas eis que vem uma nova escola. Não querem mais o Ocidente, querem demolir a obra de Pedro, o Grande, querem retomar o caminho do deserto. Esquecidos do que o Ocidente fez por nós, ingratos com o grande homem que nos civilizou, com a Europa que nos instruiu, renegam a Europa e o grande homem; e, em seu ardor apressado, esse patriotismo de recente data já nos proclama os filhos diletos do Oriente. Que necessidade, dizem, temos de buscar luzes junto aos povos do Ocidente? Não temos aqui mesmo todas as sementes de uma ordem social infinitamente preferível à da Europa? E se deixássemos o tempo fazer o seu trabalho? Abandonados a nós mesmos, à nossa razão lúcida, ao princípio fecundo oculto nas entranhas da nossa poderosa natureza, e sobretudo à nossa santa religião, teríamos logo superado todos esses povos, entregues ao erro e à mentira. $\mathrm{E}$ o que tínhamos mesmo a invejar ao Ocidente? Suas lutas religiosas, seu papa, sua cavalaria, sua inquisição? Grande coisa, com efeito! Por acaso é o Ocidente a pátria da ciência e de todas as coisas profundas? É o Oriente, sabemo-lo. Retiremo-nos portanto a esse Oriente com que topamos em toda parte, do qual outrora extraímos as nossas crenças, nossas leis, nossas virtudes, tudo que fez de nós o povo mais poderoso da terra. $O$ velho Oriente está indo embora: pois então, não somos seus herdeiros naturais? Daqui em diante é entre nós que vão se perpetuar essas admiráveis tradições, vão se realizar todas essas grandes e misteriosas verdades das quais ele é depositário desde a origem de tudo. Agora vós compreendeis de onde veio a borrasca que se abateu sobre mim naquele dia, e vedes que está se operando no nosso meio, no pensamento nacional, uma verdadeira revolução, uma reação apaixonada contra as 
luzes, contra as ideias do Ocidente, contra essas luzes, contra essas ideias que fizeram de nós o que somos, cujo fruto é essa própria reação, esse movimento que nos impele contra elas. Só que desta vez o impulso não vem de cima. Pelo contrário, dizem que a memória do nosso reformador real nunca foi mais venerada que hoje nas regiões supremas da sociedade. Assim, a iniciativa pertence inteiramente ao país. Aonde nos levará esse primeiro feito da razão emancipada da nação? Só Deus sabe! Contudo, quem ama seriamente seu país não pode evitar ser dolorosamente afetado por essa apostasia dos nossos espíritos mais avançados em relação às coisas que fizeram a nossa glória, a nossa grandeza; e creio que compete a um bom cidadão tentar, no máximo da sua capacidade, apreciar esse fenômeno singular.

Estamos localizados ao oriente da Europa, isso é um fato objetivo, mas nem por isso algum dia fizemos parte do Oriente. O Oriente possui uma história que nada tem em comum com a do nosso país. Ele contém, como acabamos de ver, uma ideia fecunda que, a seu tempo, trouxe um desenvolvimento imenso da inteligência, que cumprira sua missão com um poder prodigioso, mas que não está mais destinada a se apresentar de novo no palco do mundo. Essa ideia estabeleceu o princípio espiritual no ápice da sociedade; submeteu todos os poderes a uma lei suprema, inviolável, a lei do tempo; fecundou profundamente as hierarquias morais; e, por mais que tenha comprimido a vida em um compartimento restrito demais, subtraiu-a a toda ação exterior e marcou-a com uma maravilhosa profundidade. Nada disso houve entre nós. O princípio espiritual, sempre submetido ao princípio temporal, jamais sentou-se à cabeceira da sociedade; a lei do tempo, a tradição, jamais reinou exclusivamente entre nós; nossa vida jamais foi constituída de uma maneira invariável; por fim, de hierarquias morais jamais tivemos nem traço. Somos única e exclusivamente um país do Norte, e, pelas nossas ideias, tanto quanto pelo nosso clima, bem distantes do vale perfumado da Caxemira e das margens sagradas do Ganges. Algumas das nossas províncias confinam com os impérios do Oriente, é verdade, mas nossos centros não estão lá, nossa vida não está lá - e jamais estarão, 
a menos que o eixo do globo se desloque por alguma revolução astral ou um novo cataclismo lance mais uma vez as organizações mediterrâneas aos gelos do polo.

A verdade é que nós nunca consideramos a nossa história do ponto de vista filosófico. Nenhum dos grandes acontecimentos da nossa existência nacional foi bem caracterizado, nenhuma das nossas grandes épocas foi apreciada em boa-fé; daí todas essas imaginações bizarras, todas essas utopias do passado, todos esses sonhos de um futuro impossível que ora atormentam nossos espíritos patrióticos. Estudiosos alemães descobriram os nossos analistas, já faz cinquenta anos; em seguida, Karamzin contou, em estilo sonoro, os feitos e gestos dos nossos príncipes; na atualidade, escritores medíocres, hábeis antiquários, alguns poetas abortados, sem possuir nem a ciência dos alemães, nem a pena do ilustre historiador, imaginam que pintam ou restauram tempos e costumes dos quais ninguém entre nós conservou a memória ou o amor: esse é o sumário dos nossos trabalhos de história nacional. Convenhamos que é impossível tirar de tudo isso o sentimento sério dos destinos que nos aguardam. Todavia, é precisamente disso que se trata agora; são precisamente esses os resultados que atualmente constituem todo o interesse dos estudos históricos. O que o pensamento sério dos tempos em que vivemos reivindica é uma meditação severa, uma análise sincera dos momentos em que a vida se manifestou num povo com mais ou menos profundidade, em que o princípio social produziu-se em toda a sua verdade, pois aí está o futuro, aí estão os elementos do seu progresso possível. Se tais épocas são raras na vossa história, se a vida do vosso país não foi poderosa e profunda, se a lei que preside aos vossos destinos, longe de ser um princípio radioso, nutrido à luz grandiosa das glórias nacionais, não passa de uma coisa pálida e delicada, furtando-se à luz do sol nas esferas subterrâneas da vossa existência social, não afasteis a verdade, não pretendais ter vivido a vida das nações históricas, pois, sepultados no vosso sepulcro imenso, viveis uma mera vida de fóssil. Mas se, através desse nada, chegardes porventura a um momento em que a nação se sentiu vivendo para valer, em que seu coração realmente 
se pôs a palpitar, se ouvirdes a onda popular bramir e elevar-se ao vosso redor, ah!, parai, meditai, estudai, vosso esforço não será em vão: descobrireis do que o vosso país é capaz nos grandes dias, o que ele pode esperar no futuro. Tal foi entre nós, por exemplo, o momento que encerrou o drama pavoroso do interregno, onde a nação, levada ao extremo, com vergonha de si mesma, fez ouvir seu sublime grito de alarme e, depois de derrubar seu inimigo com um esforço espontâneo de todas as forças secretas do seu ser, elevou ao cimo a nobre família que reina sobre nós: momento único e que não se pode deixar de admirar, especialmente considerando o vácuo dos séculos anteriores da nossa história e a situação muito peculiar em que o país se encontrava nesse dia memorável. Vê-se que estou muito longe de exigir, como já se alegou, que se faça terra arrasada de todas as nossas lembranças.

Apenas disse, e repito, que é hora de lançar um olhar lúcido ao nosso passado, e não para dele extrair velhas relíquias em putrefação, velhas ideias que o tempo devorou, velhas antipatias há muito desagravadas pelo bom senso dos nossos príncipes e do país, mas para saber a que nos atermos dos nossos antecedentes. Foi isso que tentei fazer em um trabalho que ficou incompleto, e ao qual o artigo que indignou tão estranhamente as vaidades nacionais deveria servir de introdução. Sem dúvida que havia impaciência na expressão, excesso no pensamento; mas a emoção que domina toda a obra está longe de ser hostil à pátria: é um sentimento profundo das nossas fraquezas, expresso com dor, com tristeza, e nada mais.

Mais que qualquer um de vós, acreditai, eu prezo o meu país, ambiciono a sua glória, sei apreciar as qualidades eminentes da minha nação; porém, também é verdade que o sentimento patriótico que me anima não é constituído exatamente do mesmo modo que aquele cujos gritos transtornaram a minha existência tranquila e novamente lançaram, no oceano das misérias humanas, a minha barca encalhada ao pé da cruz. Não aprendi a amar meu país de olhos fechados, fronte curvada, boca fechada. Acho que só se pode ser útil ao seu país sob a condição de enxergá-lo claramente; creio que passou o tempo dos amores cegos e que, hoje em dia, devemos à pátria 
acima de tudo a verdade. Eu amo o meu país como Pedro, o Grande, ensinou-me a amá-lo. Asseguro que não tenho esse patriotismo beato, esse patriotismo preguiçoso que dá um jeito de ver tudo cor-de-rosa, que se embala com suas ilusões e que, nos dias atuais, infelizmente acomete muitos dos nossos bons espíritos. Penso que, se viemos após os outros, é para fazer melhor que os outros, e não para recair nas suas faltas, seus erros, suas superstições. Na minha opinião, estaríamos cometendo um estranho equívoco com o papel que nos coube se nos reduzíssemos a repetir ineptamente toda a longa série de loucuras perpetradas pelas nações menos favorecidas que nós, a reencetar todas as calamidades sofridas por elas. Considero que a nossa situação é afortunada, contanto que a saibamos apreciar; é um belo privilégio poder contemplar e julgar o mundo da altura de um pensamento desatrelado de paixões desenfreadas, lamentáveis interesses que alhures turvam a visão do homem e falseiam o seu julgamento. E tem mais: tenho a íntima conviç̧ão de que nós somos convocados a resolver a maioria dos problemas da ordem social, concretizar a maioria das ideias surgidas nas sociedades velhas, decidir as mais graves questões que preocupam o gênero humano. Já o disse várias vezes, e me compraz repeti-lo: de alguma forma somos constituídos, pela própria natureza das coisas, em um verdadeiro júri de muitos processos que tramitam perante os grandes tribunais do espírito humano e da sociedade humana.

Com efeito, vede o que se passa nos países que eu talvez tenha louvado demais, mas que nem por isso deixam de ser os exemplares mais completos de toda espécie de civilização. Já se viu isto em demasia: uma ideia nova vem a eclodir; no mesmo instante, todos os egoísmos estreitos, vaidades pueris, partidos obstinados que se movem à superfície da sociedade apropriam-se dela, a travestem, a desnaturam, e, no momento seguinte, triturada por esses agentes diversos, ela é retirada a essas regiões abstratas aonde são tragadas todas as poeiras estéreis. Entre nós, nada desses interesses apaixonados, dessas opiniões formadas, desses preconceitos constituídos; aproximamo-nos de cada ideia nova como espíritos virgens. Em nossas instituições (obras espontâneas dos nossos prínci- 
pes ou débeis vestígios de uma ordem de coisas lavrada pela sua charrua todo-poderosa), em nossos costumes (bizarra mescla de imitação desajeitada e farrapos de uma existência social há muito esgotada), em nossas opiniões (que debalde ainda tentam se fixar nas coisas mais ínfimas), nada se opõe à realização imediata de todo os bens que a Providência destina à humanidade. Basta que uma vontade soberana se pronuncie entre nós para que todas as opiniões se apaguem, todas as crenças esmoreçam, todos os espíritos se abram ao pensamento novo que lhes é oferecido. Não sei, talvez tivesse valido mais atravessar todas as provações percorridas pelos outros povos cristãos, tirando daí, como eles, forças, energias, métodos novos, e quiçá a nossa posição isolada nos teria preservado das calamidades que acompanharam a longa e laboriosa educação desses povos; porém, o que é certo é que agora não é mais isso que está em jogo; no momento, deve-se visar a apreender bem o caráter atual do país tal como ele é dado, tal como ele está constituído pela própria natureza das coisas, e disso tirar todo o partido imaginável. A história não é mais nossa, é verdade, mas a ciência nos pertence; não seríamos capazes de recomeçar todo o trabalho do espírito humano, mas podemos participar dos seus trabalhos posteriores; o passado não está mais em nosso poder, mas o futuro é nosso. Indubitavelmente, uma grande parte do universo é oprimida pelas suas tradições e memórias; não lhes invejemos o círculo restrito em que eles se debatem; com certeza, existe no coração da maior parte das nações um sentimento profundo da vida consumada a dominar a vida atual, uma memória obstinada dos dias transatos a preencher os dias atuais. Deixemo-los lutar com seu passado inexorável.

Nós nunca vivemos sob a pressão fatal da lógica do tempo; nunca uma força todo-poderosa nos precipitou nos abismos que os séculos cavam em frente aos povos. Aproveitemos a imensa vantagem de obedecer apenas à voz de uma razão esclarecida, uma vontade refletida. Saibamos que, para nós, não existe uma necessidade irrevogável; que, graças aos céus, não nos encontramos na veloz ladeira que arrasta tantas outras nações aos seus destinos desconhecidos; que nos é dado medir 
cada passo que damos, examinar cada ideia que vem aflorar na nossa inteligência; que nos é permitido aspirar a prosperidades ainda mais vastas que as que sonham os mais ardentes ministros do progresso; e que, para chegar a esses resultados definitivos, só precisamos de um único ato soberano dessa vontade suprema que contém todas as vontades da nação, que exprime todas as aspirações dela, que mais de uma vez já lhe abriu novos caminhos, descortinou novos horizontes diante dos seus olhos e fez descer à sua inteligência novas luzes. $E$ então, é um futuro mesquinho o que eu estou oferecendo à minha pátria? Porventura julgais que são destinos sem glória que evoco em seu favor? Contudo, esse grande futuro que se realizará, esses belos destinos que se cumprirão, não duvideis, serão apenas o resultado dessa natureza peculiar do povo russo, assinalada pela primeira vez no artigo fatal. ${ }^{2}$ Todavia, tenho pressa em proclamá-lo, e sinto-me sortudo por ser levado a fazer essa afirmação. Sim, havia exagero nessa espécie de acusação lançada contra um grande povo cujo único crime era, no fim das contas, ter sido relegado aos confins de todas as civilizações do mundo, longe das regiões onde as luzes tiveram naturalmente de se acumular, longe dos lumes de onde elas jorraram por tantos séculos; havia exagero em não reconhecer que viemos ao mundo em um solo que as gerações anteriores não haviam revolvido, não haviam fecundado, onde nada nos falava das eras transcorridas, onde não havia nenhum traço de um mundo novo; havia exagero em não reconhecer o mérito dessa Igreja tão humilde, por vezes tão heroica, que é o único consolo do vazio dos nosso anais, a quem cabe a honra de cada ato de coragem, cada bela devoção dos nossos pais, cada

\footnotetext{
2 Mas sabe-se, afinal, o que era esse artigo? Era uma carta íntima escrita a uma mulher, vários anos antes, sob a impressão de um sentimento doloroso, uma imensa decepção, que a indiscreta vaidade de um jornalista revelou ao público; que, lida e relida mil vezes antes da impressão, no original bem mais duro que a fraca tradução em que foi publicada, nunca provoca o mau humor de quem quer que seja, nem mesmo dos patriotas mais idólatras; e na qual, por fim, em meio a algumas páginas de uma devoção profunda, estava encaixado um estudo histórico onde a velha tese da superioridade dos países do ocidente era reproduzida com um certo ardor; talvez com exagero. Esse era o escrito detestável, o panfleto incendiário que atraiu ao autor a ira pública, a mais estranha das perseguições. ([N. do E. da Bibliothèque russe et slave:] Nota de Tchaadaiév, desconhecida por Ivan Gagárin, e restituída nas edições do século XX.)
} 
bela página da nossa história; enfim, havia talvez exagero em entristecer-se por um momento com a sorte de uma nação que viu nascer dos seus flancos a poderosa natureza de Pedro, o Grande, o espírito universal de Lomonóssov e o gênio gracioso de Púchkin.

No entanto, depois disso havemos de convir que as fantasias do nosso público são admiráveis.

É lembrado que, um momento após a desastrosa publicação de que estamos falando, um novo drama foi representado na nossa cena. Pois bem, nunca uma nação foi fustigada de tal sorte, nunca um país foi tão arrastado na lama, nunca se jogou tanta imundície na cara de um público e, contudo, nunca um sucesso foi mais completo. Então o espírito sério que meditou profundamente sobre o seu país, a história, o caráter do seu povo estará condenado ao silêncio por não conseguir fazer ouvir pela boca de um histrião o sentimento patriótico que o oprime?! Afinal, o que nos deixa tão complacentes com a lição cínica da comédia e tão melindrosos com a palavra austera que vai ao fundo das questões? É necessário dizer que ainda não temos nada além de instintos patrióticos; estamos muito longe ainda do patriotismo refletido das velhas nações amadurecidas pelos trabalhos da inteligência, esclarecidas pela luz, pelas meditações da ciência; ainda prezamos nosso país ao modo desses povos adolescentes ainda não atormentados pelo pensamento, ainda em busca da ideia que lhes pertença, do papel que eles serão chamados a cumprir no palco do mundo; nossas forças intelectuais ainda não se exerceram nas coisas sérias; em uma palavra, o trabalho do espírito foi praticamente nulo entre nós até hoje. Chegamos com uma rapidez impressionante a um certo grau de civilização que faz jus à admiração da Europa. Nosso poder é o terror do mundo, nosso império se estende por um quinto do globo; mas tudo isso, cumpre admitir, devemos apenas à vontade enérgica dos nossos príncipes, secundada pelas condições físicas da terra que habitamos.

Talhados, moldados, criados pelos nossos soberanos e nosso clima, foi somente à força de submissão que nos tornamos 
um grande povo. Percorrei nossos anais de uma ponta à outra: encontrareis em cada página a ação profunda do poder, a influência incessante do solo, e quase nunca a da vontade pública. Todavia, também é verdade que, abdicando do seu poder nas mãos dos seus mestres, cedendo à natureza da sua terra, 0 povo russo deu provas de uma elevada sabedoria, ao reconhecer assim a lei suprema dos seus destinos: singular resultado de dois elementos de ordem diferente, que ele não poderia negligenciar sem falsear seu ser, sem comprimir o próprio princípio do seu progresso possível. Uma rápida olhada à nossa história do ponto de vista onde nos colocamos irá, espero eu, mostrar-nos essa lei em toda a sua evidência.

Existe um fato que domina soberanamente nossa marcha através dos séculos, percorre nossa história inteira, compreende de certa forma toda a sua filosofia, produz-se em todas as épocas da nossa vida social e lhes determina o caráter, é ao mesmo tempo o elemento essencial da nossa grandeza política e a verdadeira causa da nossa impotência intelectual: esse fato é o fato geográfico.

[Aqui se interrompe o manuscrito, e nada indica que ele tenha sido um dia continuado. - Ivan Gagárin]

Recebido em: 21/05/2020

Aceito em: 19/07/2020

Publicado em setembro de 2020 